\title{
EFFECTIVE METHODS OF TEACHING ENGLISH
}

\author{
Mr. Hitendra H Vyas \\ "The first exercises in the new material should be very easy; not until later should more difficult \\ material be introduced and practiced." - Comenius
}

According to methodology there are plenty of teaching methods that can be applied in the education process however not all of them are effective, in terms of young learners with learning difficulties, and can guarantee their success in learning English.

\section{Teaching principles}

Before identifying appropriate teaching techniques that would help young learners with their learning difficulties certain teaching principles or strategies, that enable teacher to create suitable conditions for students to acquire a foreign language easily, should be mentioned:

- Systematic approach

- Predictable and friendly environment

- Motivation

- Interventions

- Clear instructions

- Review

The most important teaching principle is the systematic approach that is based on structured or sequential teaching. Then the teacher should provide a predictable, consistent and friendly environment to support their children and let them feel comfortable in lessons. Hand in hand with support comes motivation that is used to encourage students to learn English. Particularly for young learners with learning difficulties, it is essential to apply so called interventions such as accommodation and modification. Another significant principle is the clarity of instructions which 
means that all directions should be explicit and, even better, both orally and visually presented. Last but not least is review and regular repetition that vitally help children to acquire what they have learnt. The above list of teaching principles is not complete. What could be added is for example "time supply" which means that the teacher gives the children sufficient time to do a task.

\section{Teaching techniques}

According to several researchers, it is not easy for the teacher to differentiate between students with learning disabilities and those with learning difficulties (sometimes called "slow learners"). According to an article published by The International Dyslexia Association many students have difficulties learning a new language system. This does not mean that they are dyslexic or that they have a learning disability. Just as there are some students who have particular strengths in math, science, or any other discipline, some students have particular strengths in learning languages. The teacher should be aware of this and whenever they realize the students' weaknesses (difficulties) be able to provide appropriate pedagogical help as otherwise these difficulties start to pile up and later on they can have a negative influence on young learners. One result of accumulating difficulties can be following: even when young learners try to do their best at English lessons, they are not successful. This failure causes them stress and, slowly or quickly, they lose their self-confidence and self-esteem.

Thus, the teacher must know how to prevent pupils with these difficulties from experiencing problems and direct them a way to manage to accommodate the language. Among the most efficient ways (teaching methods) that the teacher can apply are: Multi-sensory techniques, Metacognition, Total Physical Response (TPR), discovery techniques and presentation techniques.

\section{Presentation techniques}

The latter mentioned method uses different objects (instruments) in the classroom to create connections between "abstract" vocabulary and "real" things. Thus these techniques help to build learners background knowledge with using their senses to learn about a given subject. Among the presentation techniques belong:

- Realia - real objects are used as examples

- Pictures - explaining the meaning of vocabulary items through pictures 
- Mime, action and gesture - this technique uses a human body to express for example grammatical points, verbs or tenses

- Contrast - presenting the meaning of a certain word by contrasting it with the opposite one

- Enumeration - general and specific meaning of words

- Explanation - giving a definition

- Translation - the easiest technique but not productive

An important part of presentation techniques (introducing new words) is pronunciation which should not be underestimated.

\section{Total Physical Response (TPR)}

This technique was first invented in 1960s by James Asher, an American professor of psychology. This technique is based on command activities. The teacher gives verbal comprehensible stimulus (instructions) and students act or (physically) respond according to it. The method shows the evidence of the input and output of the learning process. The students thus learn language through actions rather than through drills. Concerning the students' output reaction, their "understanding" is predominantly expressed by acting and speaking skill is stifled. This characteristic of TPR can be employed for very young learners who cannot yet make a whole sentence in foreign language but they understand due to context.

As well as the advantage of the technique can be taken when students have a so called 'silent period', which means that they do not speak but respond in a different way, e.g. pointing to a picture, performing, gesturing or nodding or just responding with a simple "yes" or "no" to express that they understand and participate in the lesson.

\section{Discovery techniques}

The most practical and encouraging example of active learning are discovery techniques that are based on the fact that students have to work out rules and meanings for themselves. These techniques helped students activate their previous knowledge and share what they know. By involving students with words, it is likely to help them to learn and remember them. In other words, students discover the ways in which the language works and they learn through this process the function of language therefore these techniques are valuable. 
Moreover this technique has a good pedagogical and methodological effect on students as they are more involved in the learning process and are aware of language. The main discovery techniques are: matching tasks, mind mapping, word in context, gap filling etc. The matching discovery activities are based on labeling pictures or things. Students are asked to match pictures with appropriate words. If they do not know the words they look up their meaning in a bilingual dictionary, which helps them to do correct combinations, or students can work in pairs or groups to help each other with the unknown words.

The second mentioned discovery technique is the mind mapping activity. Mind mapping helps students to group words according to their characteristics and their relations, so students create a spidergram that express links between the words. The "word in context" activity is very suitable for advanced students because they learn the meaning of certain words through a text. The information in the text works as background that helps students to deduct the proper meaning of the words. The further mentioned activity gap filling or fill-in passage is an alternation to the previous activity. Students are given a text with missing words and they have to think of a suitable word that would fit into the gap. As a help for young learners the gaps in the text are provided with pictures.

\section{Multi-sensory techniques}

The most commonly used approach that benefits young learners who have difficulties learning a foreign language is multi-sensory techniques. These techniques focus on teaching students through all sensory channels (auditory, visual and tactile/kinaesthetic), which generally helps to support their weaker channels by using their stronger ones. This method is sensible for teaching pronunciation, spelling, reading and other skills. Besides the multi- sensory technique enables young learners to consciously memorise and retrieve information. Schneider and Crombie (2003) announced a motto of multi-sensory techniques that is 'Hear it, see it, say it, write it, act it out' and make learning as active as possible.

Some practical examples of multi-sensory techniques: simultaneous oral spelling, racing sandpaper numbers/letters, writing with a finger into sand or on someone's back etc. The technique of simultaneous oral spelling consists of five steps. Firstly a young learner says a word, which means in terms of sensory input that the student hears and feels himself saying the word. Then the 
young learner spells the word aloud and doing this he hears the sequence of letters within the word. As a third step, the student writes down the word saying the letters aloud and as a result of this he hears the letters again and as well as feels his hand write the letters' shapes. The final step is checking what was written. This step employs the visual channel because the young learner sees the word appear on the page and then compare it with the original.

\section{Simultaneous oral spelling - illustrative picture}

Multi-sensory techniques are employed to integrate the learning of the sound of a letter, its shape on the written page and the feel of writing it in cursive script, so that a secure soundsymbol relationship is established for reading and spelling. (Townend, 2006) The other example of multi-sensory techniques - tracing sandpaper numbers or letters - moreover involves the tactile channel, which means that not only seeing numbers and hearing them but also feeling their shapes helps the young learner to make a parallel link between the symbol (number or letter) and its sound.

\section{Metacognition}

In a sophisticated way, metacognition can be defined as "instructional approaches emphasizing awareness of the cognitive processes that facilitate one's own learning and its application to academic and work assignments". (Lokerson, 1992) Typical metacognitive techniques include systematic rehearsal of steps or conscious selection among strategies for completing a task, and thus students are aware of learning as a process and of what will facilitate learning. Schneider and Crombie (2003) called metagonition a technique that provides "problemsolving strategies".

Thus, metacognition is a method that can be generously used and be more successful when teaching older learners who have a certain degree of knowledge and have mastered cognitive strategies of learning foreign language.

\section{Mnemonic devices}

Schneider and Crombie (2003) offer useful mnemonic devices that support metacognitive, actually metalinguistic, skills and thus help students remember and retrieve information more easily.

Here is a list of mnemonic devices (Schneider and Crombie 32-42): 
Sound clues - help the memorisation and recall of pronunciation patterns and vocabulary (example: the student links the letter sound with a cultural-semantic association in the first language /to improve pronunciation/ - skirt $=$ sukně $\mathrm{x}$ shirt $=$ košile)

Letter-shape clues - help memorise and recall spelling patterns (non-phonetic words or word parts) and vocabulary (example: linking the letter shape of the letter that causes spelling problems with an association in the first language or an important keyword that entails it - such as sounds $\{\mathrm{p}\}$ and $\{\mathrm{b}\} ;\{\mathrm{p}\}=$ 'top' part is rounded, $\{\mathrm{b}\}=$ 'bottom' part is rounded)

Crazy stories - difficult spelling words are integrated in groups of up to five in a story that students make up individually (the crazier the story and the shorter, the better for later retrieval) - good to illustrate with picture mnemonics (example: 'When two vowels go walking, the first one does the talking.' - beat, boat, read etc..

Picture clues - visual illustrations done by student or by teacher help memorise and recall difficult new vocabulary and class activities

Acronyms - the letters of an entire word each stand for a concept to memorise and recall (e.g. a syllable pattern or study device) (example: KISS = Keep It Short and Simple)

Keywords - (belong to the learners' active vocabulary) help retrieve pronunciation of letters, meanings of words or sequences of a grammatical pattern; a keyword sentence helps to memorise and recall syllable patterns of learning steps

Songs and sounds - a melody or entire song helps memorise and recall pronunciation, vocabulary or grammar - a sound helps recall specific language patterns (e.g. sentence structure) (example: remaining a young learner of missing ending $-\mathrm{s}$ in singular present tense the teacher uses the sound of hissing snake)

Gesture and motion clues - signals meaning or a pronunciation, spellchecker or reading comprehension rule (example of gesture to remind about spellchecker rule - finger-tapping technique, which is tapping one finger per sound in a syllable) 


\section{Conclusion}

Primarily the teaching principles (structured, sequential, cumulative, repetitive, instructions, motivation, environment) should be taken into consideration because they work as valuable facilitators in the education process. Then the second factor is the good choice and application of teaching techniques. Among the most useful techniques that are also practised with the students are namely presentation techniques, total physical response, discovery techniques, multi-sensory techniques and metacognition. All of these techniques offered a wild range of activities that stimulate and involve students in the learning process.

Multi-sensory techniques, discovery techniques and metacognition are useful teaching techniques concerning young learners with learning difficulties. The advantage of multisensory techniques is involving all students' senses into the learning process through using the stronger channels to support the weaker ones. These techniques facilitate the students' brain to create besides the visual and auditory memories the tactile and kinetic ones. In terms of discovery techniques the advantage is in the self discovery or awareness process when young learners tackle tasks on their own and thus they learn through what they have detected by themselves. As well as metacognition has its benefits, more preciously mnemonic devices that help a lot to encourage and support young learners to overcome their problems with foreign language. 


\section{Bibliography}

Ganshow, Leonore, and Schneider, Elke. "At-risk students and the study of a foreign language in school." Fact Sheet 25, 2005.

Harmer, James. The Practice of English Language Teaching. Harlow: Longman, 2001.

Krashen, Stephen, D. Second Language Acquisition and Second Language Learning. Pergamon Press Inc., 1981.

Lokerson, Jean. Learning Disabilities: Glossary of Some Important Terms. ED352780, 1992, Education Resources Information Center. 4 March 2006 < http://www.eric.ed.gov>.

Schneider, Elke, and Crombie, Margaret. Dyslexia and Foreign Language Learning. London: David Fulton Publishers, 2003.

Townend, Janet. Principles of Teaching - The DI Literacy Programme. The Dyslexia Institute. 4 March 2006 < http://www.dyslexia-inst.org.uk/articles/prin teach.htm>.

\section{Hitendra H Vyas, \\ S. V. Arts College, Ahmedabad, Gujarat, India. hitendrahvyas@gmail.com}

